\title{
Inspiratory Muscle Training in the Intensive Care Unit: A New Perspective
}

\author{
Rodrigo Marques Tonella ${ }^{\mathrm{a}, \mathrm{d}}$, Ligia Dos Santos Roceto Rattia, Lilian Elisabete Bernardes Delazaria \\ Carlos Fontes Junior ${ }^{\mathrm{a}}$, Paula Lima Da Silva ${ }^{\mathrm{a}}$, Aline Ribeiro Da Silva Herran ${ }^{\mathrm{a}}$, \\ Daniela Cristina Dos Santos Faez ${ }^{\mathrm{a}}$, Ivete Alonso Bredda Saad ${ }^{\mathrm{a}}$, \\ Luciana Castilho De Figueiredo ${ }^{\mathrm{a}}$, Rui Moreno ${ }^{\mathrm{b}}$, Desanka Dragosvac ${ }^{\mathrm{c}}$, \\ Antonio Luis Eiras Falcao ${ }^{\mathrm{c}}$
}

\begin{abstract}
Background: Prolonged use of mechanical ventilation (MV) leads to weakening of the respiratory muscles, especially in patients subjected to sedation, but this effect seems to be preventable or more quickly reversible using respiratory muscle training. The aims of the study were to assess variations in respiratory and hemodinamic parameters with electronic inspiratory muscle training (EIMT) in tracheostomized patients requiring $\mathrm{MV}$ and to compare these variations with those in a group of patients subjected to an intermittent nebulization program (INP).
\end{abstract}

Methods: This was a pilot, prospective, randomized study of tracheostomized patients requiring MV in one intensive care unit (ICU). Twenty-one patients were randomized: 11 into the INP group and 10 into the EIMT group. Two patients were excluded in experimental group because of hemodynamic instability.

Results: In the EIMT group, maximal inspiratory pressure (MIP) after training was significantly higher than that before $(P=0.017)$, there were no hemodynamic changes, and the total weaning time was shorter than in the INP group $(\mathrm{P}=0.0192)$.

Conclusion: The EIMT device is safe, promotes an increase in MIP, and leads to a shorter ventilator weaning time than that seen in patients treated using INP.

Keywords: Diaphragm; Respiratory insufficiency; Ventilator weaning; Intensive care

Manuscript submitted August 29, 2017, accepted September 18, 2017

a School of Medical Sciences, Intensive Care Unit of Clinical Hospital, State University of Campinas (UNICAMP), Campinas, Sao Paulo, Brazil

${ }^{b}$ Neurological Intensive Care Unit, Sao Jose Hospital, Lisboa, Portugal

${ }^{\text {'S }}$ chool of Medical Sciences, Intensive Care Unit of Clinical Hospital, Department of Surgery, State University of Campinas (UNICAMP), Campinas, Sao Paulo, Brazil

${ }^{\mathrm{d} C}$ Corresponding Author: Rodrigo Marques Tonella, School of Medical Sciences, Intensive Care Unit of Clinical Hospital, State University of Campinas (UNICAMP), Vital Brazil St. 251, Sao Paulo 13083-888, Brazil.

Email: digomato@gmail.com

doi: https://doi.org/10.14740/jocmr3169w

\section{Introduction}

The main goals of invasive ventilatory support are to promote normal alveolar ventilation and effective gas exchange, to treat the underlying disease, and to reverse respiratory failure [1]. However, the disuse of the respiratory muscles that occurs alongside such controlled ventilation weakens the muscles [2] and decreases diaphragm strength in a manner that is logarithmically proportional to the duration of mechanical ventilation (MV) [3] and to the use of sedation and muscle blockers [4]. Episodes of sepsis, extended MV, and severe polyneuropathy [5] exacerbate the harmful effects on respiratory muscular function and can lead to long dependence from MV [6].

The process of weaning from MV involves the patient initially spending approximately $40 \%$ of their time on MV [7]. Unfortunately, especially when the weaning process started late, the significant loss of muscle strength means that between $5 \%$ and $15 \%$ of patients being weaned repeatedly fail to regain respiratory autonomy [6].

The extended use of MV is associated with high daily cost of hospitalization and a higher mortality [8]; therefore, pulmonary rehabilitation interventions have been decreasing hospitalization time and substantially reducing hospital costs [9].

Respiratory muscle training reverses weakness and improves endurance [10]. The training can result in a significant increase in the maximal inspiratory pressure (MIP) [11], as well as successful weaning of patients who have failed repeatedly [12]. Muscle training is safe, with no adverse hemodynamic or respiratory repercussions that would necessitate discontinuing the procedure, even in patients whose condition is severe [13].

New technologies are available for respiratory muscle training. Electronic devices play a key role in increasing the respiratory performance of recreational runners [14]. The safety of these devices using inspiratory loads of up to $60 \%$ MIP has been confirmed in normal individuals. Specifically, when this limit was applied, the resulting hemodynamic variations were within the normal range [15].

Souza et al [16] used an electronic device for inspiratory muscle training (IMT) in a tracheostomized patient on MV who had a neuromuscular disease; the investigators observed an increase in MIP, detected no significant hemodynamic repercus- 
Table 1. Inclusion Criteria

\begin{tabular}{ll}
\hline Criteria & Requirements \\
\hline Age & $>18$ years old \\
Partial arterial oxygen tension & $>60 \mathrm{~mm} \mathrm{Hg}$ \\
Fraction of inspired oxygen & $\leq 0.6$ \\
Oxygen saturation index & $\geq 100$ \\
Mean arterial pressure & $\geq 80 \mathrm{~mm} \mathrm{Hg} \leq 110 \mathrm{~mm} \mathrm{Hg}$ \\
Analgesia and sedation & Without analgesia/sedation more than $24 \mathrm{~h}$ \\
Ventilatory modality & Assisted $/$ controlled or spontaneous \\
Pressure support ventilation & $\geq 10 \mathrm{~cm} \mathrm{H}_{2} \mathrm{O}$ \\
Positive end-expiratory pressure & $\leq 10 \mathrm{~cm} \mathrm{H} \mathrm{H}_{2} \mathrm{O}$ \\
Respiratory rate & $\leq 30 \mathrm{breaths} / \mathrm{min}$ \\
Arterial oxygen saturation & $\geq 90 \%$ \\
Body temperature & $\geq 36.5^{\circ} \mathrm{C} \leq 38.5^{\circ} \mathrm{C}$ \\
Body mass index & $\leq 40 \mathrm{~kg} / \mathrm{m}^{2}$ \\
\hline
\end{tabular}

sions, and reported successful invasive weaning from MV.

With this in mind, we assessed variation in respiratory and hemodynamic parameters in tracheostomized patients who were subjected to electronic IMT (EIMT). Further, this group was compared with a group of patients subjected to an intermittent nebulization program (INP); the groups were compared in terms of MIP, rapid shallow breathing index (RSBI), duration of $\mathrm{MV}$, and total weaning time.

\section{Methods}

This was a pilot, prospective, randomized study involving tracheostomized patients hospitalized in the intensive care unit (ICU) of the Clinical Hospital at the State University of Campinas. The Research Ethics Committee of the same institution (report No. 403/626) approved this study. The patients' legal representatives read, accepted, and signed an informed consent form (ICF), allowing patient enrollment in the study (registered in The Brazilian Clinical Trials - REBeC, number U1111-1156-3177).

From October 2013 to January 2014, 25 consecutive patients were selected. Twenty-one tracheostomized patients meeting the inclusion criteria were enrolled (Table 1). Patients were excluded from this study when presented injury of phrenic nerve, neuromuscular disease, or musculoskeletal disorders, necessity of more than 1 aspiration per hour, or who had used home MV before hospitalization.

The patients were randomized into two groups: INP and EIMT. The randomization was performed using closed envelopes, the selection being performed by one of the authors of the study accompanied by an employee of the same institution who was not participating in the research. Weaning success was defined as breathing without MV for 48 consecutive hours. Prior to data collection, each patient received physical therapy comprising bronchial hygiene therapy, tracheal and oral cavity aspiration, and positioning in bed with the head lifted at an angle of at least $30^{\circ}$.

Three MIP readings were obtained from each patient daily using a digital manovacuometer (MVD300; GlobalMed ${ }^{\circledR}$, MDI Produtos e Sistemas Ltda Novo, Hamburgo, Brazil). The measurement involved a one-way valve connected to both the tracheostomy tube and the equipment, a 20-s occlusion, a 1-min break between measurements, and selection of the highest MIP value. The RSBI was also checked daily using a ventilometer (Wright ${ }^{\circledR}$ Mark-8, inspector inspire health Ltd, Hertford, England).

The fraction of inspired oxygen was adjusted to $100 \%$ for 2 min before the MIP and RSBI measurements were obtained.

In the INP group following institutional protocol, the patients were subjected to an INP using a T-piece for a progressively increasing duration, until they had completed $48 \mathrm{~h}$ of respiratory autonomy on continuous nebulization. INP was discontinued when the patient showed two or more of the clinical criteria characterizing respiratory failure: respiratory rate over than 35 cycles/min; oxygen arterial saturation less than $90 \%$; heart rate over than 130 beats/min; systolic blood pressure over than $180 \mathrm{~mm} \mathrm{Hg}$ or less than $90 \mathrm{~mm} \mathrm{Hg}$; signs and symptoms like agitation, sweating, change in consciousness level and thoracoabdominal asynchrony.

In the EIMT group, patients underwent training using a POWER breathe ${ }^{\circledR}$ KH2 (IMT Technologies Ltd, Birmingham, England) electronic inspiratory training device. The manual mode was selected and 30 repetitions were divided into three series of 10 with a 1-min break between each series. EIMT was performed twice a day using a resistive load of $30 \%$ of the initial MIP and readjusted daily, with a $10 \%$ increase on each training day.

Hemodynamic and respiratory parameters were monitored before and after each training session: heart rate (HR), mean arterial pressure (MAP), arterial oxygen saturation $\left(\mathrm{SpO}_{2}\right)$, and respiratory rate (RR). Additionally, in the EIMT group, hemodynamic and respiratory parameters were monitored during training (Table 2).

In the EIMT group, the training was to be discontinued if 
Table 2. Demographics of the Studied Population

\begin{tabular}{|lll}
\hline Demographics & INP group $(\mathbf{N}=\mathbf{8})$ & EIMT group $(\mathbf{N}=\mathbf{1 1})$ \\
\hline $\begin{array}{l}\text { Median age (years) } \\
\text { Gender }\end{array}$ & 46.5 & 58.0 \\
$\quad$ Male & $\mathrm{N}=7$ & $\mathrm{~N}=8$ \\
$\quad$ Female & $\mathrm{N}=1$ & $\mathrm{~N}=3$ \\
TI rationale & $\mathrm{N}=4$ & $\mathrm{~N}=4$ \\
$\quad$ Respiratory failure & $\mathrm{N}=3$ & $\mathrm{~N}=5$ \\
$\quad$ Decrease in consciousness level & $\mathrm{N}=1$ & $\mathrm{~N}=2$ \\
$\quad$ Post-operative complications & $\mathrm{Mean} \pm \mathrm{SD}$ & $\mathrm{Mean} \pm \mathrm{SD}$ \\
$\quad$ & $20.2 \pm 7.2$ & $20.9 \pm 5.4$ \\
APACHE II & $7.7 \pm 4.4$ & $7.13 \pm 5.8$ \\
\hline SOFA &
\end{tabular}

INP: intermittent nebulization program; EIMT: electronic inspiratory muscle training; N: number of patients; TI: tracheal intubation; SD: standard deviation; APACHE II: acute physiology and chronic health disease classification system II; SOFA: sequential organ failure assessment.

the patient showed two or more of the clinical criteria characterizing respiratory failure: respiratory rate over than 35 cycles/min; oxygen arterial saturation less than 90\%; heart heat over than 130 beats/min; systolic blood pressure over than 180 $\mathrm{mm} \mathrm{Hg}$ or less than $90 \mathrm{~mm} \mathrm{Hg}$; signs and symptoms like agitation, sweating, change in consciousness level, and thoracoabdominal asynchrony.

SPSS version 13.0 for Windows was used for statistical analysis. No normal variable distribution was found using the Kolmogorov-Smirnov test. A descriptive analysis of numerical and categorical variables was performed in both groups. The Wilcoxon test was used to compare related variables, and the Mann-Whitney test for independent samples. $\mathrm{P}$ values $<0.05$ were considered statistically significant.

Figure 1 shows the study flowchart, as well as the number of patients studied.

\section{Results}

Twenty-five patients were selected from October 2013 to January 2014; four were excluded because they failed to submit an ICF signed by legal representatives. Twenty-one patients were randomized: 11 into the INP group and 10 into the EIMT group. Two patients were excluded in experimental group because of hemodynamic instability. In both groups, one patient died (Fig. 1). The demographics of the study population are presented in Table 2. There were no significant differences between the groups in terms of demographics.

Although the HR, MAP, RR, and $\mathrm{SpO}_{2}$ showed variation during training in the EIMT group, these were within normal values and did not necessitate discontinuation of the treatment.

Table 3 shows the RSBI and MIP values obtained before and after training in both groups. The groups did not differ in terms of RSBI values either before or after the respective treatment. In both groups, MIP increased after the training; however, the increase was significant only in the EIMT group when the value before training was compared with that after training $(\mathrm{P}<0.017)$.

The groups did not differ in terms of MV time with $21.8 \pm$ 9.8 days to INP group and $14.5 \pm 10$ days for EIMT group ( $\mathrm{P}$ $=0.082)$; however, the total weaning time was shorter in the EIMT group than in the INP group $(\mathrm{P}=0.0192)$, with $9.4 \pm$ 6.47 days for INP group and $3.5 \pm 1.6$ days for EIMT group.

\section{Discussion}

Our findings suggest that EIMT can be used safely and possibly effectively in tracheostomized patients who are on MV and are being treated in the ICU, as the HR, MAP, RR, and $\mathrm{SpO}_{2}$ were within normal values.

Selection of the study population was made easy owing to the large number of patients needing a tracheostomy tube because of difficulties with weaning. This is in accordance with the study by Cader et al [17], which treated intubated patients using a respiratory muscle training protocol, with a view to increasing the extubation success rate; however, of the 198 patients selected for their study, only 28 were randomized, as the majority of the population was subject to tracheostomy tube or died.

The selection of a $30 \%$ resistive load during EIMT was supported by the findings of Bissett et al [10], who evaluated patients on MV for 7 days or more and successfully weaned them from ventilation. The same authors noted that respiratory muscle endurance was reduced in a third of the studied patients immediately after MV withdrawal.

The findings of Cader et al [18] also supported the resistive load selected in our study. In a randomized assay, these authors employed IMT twice a day using a load that was equivalent to $30 \%$ of the MIP, with a daily $10 \%$ increase in the training load. They found an increase in the MIP and a decrease in weaning time; $87.5 \%$ of the patients in the training group were discharged from the ICU with no need for ventilatory support. Similar results were obtained in this study; total weaning 


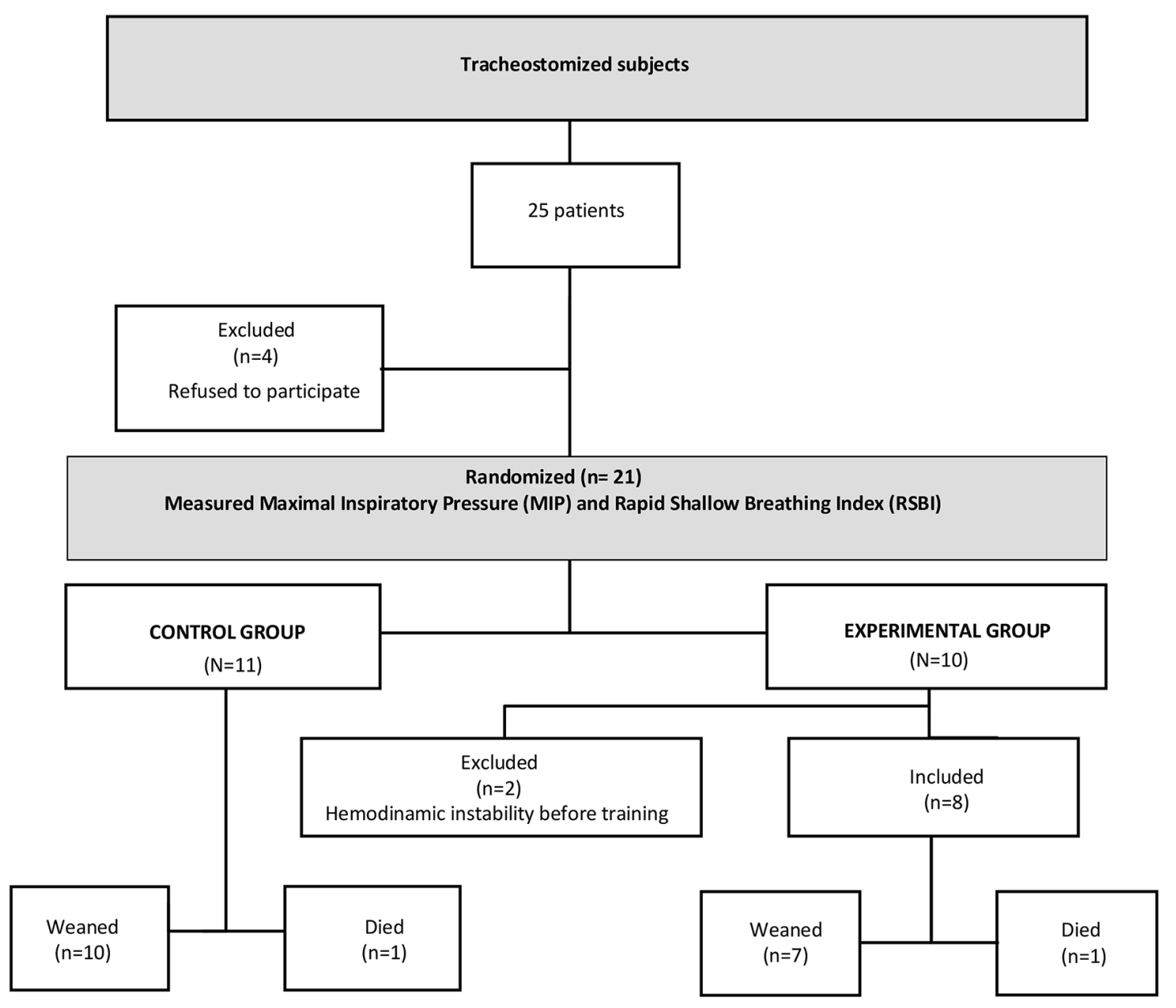

Figure 1. Study flowchart and the number of patients studied.

time was shorter in the EIMT group, and this was associated with significant MIP increase over the pre-training values (P $=0.017$ ). The proportion of ICU discharges showed a similar trend in this study, because all patients who had achieved respiratory autonomy were discharged from the ICU.

In a prospective study, Epstein et al [19] found that MVdependent patients who had been successfully weaned had an average MIP of $40 \mathrm{~cm} \mathrm{H}_{2} \mathrm{O}$. In contrast, patients for whom weaning had failed presented an average MIP of $20 \mathrm{~cm} \mathrm{H}_{2} \mathrm{O}$. In our study, the initial mean MIPs were $43 \pm 16 \mathrm{~cm} \mathrm{H}_{2} \mathrm{O}$ and

Table 3. Distribution of MIP and RSBI Values in Both Groups

\begin{tabular}{llllll} 
& \multicolumn{2}{c}{ INP group } & & \multicolumn{2}{c}{ EIMT group } \\
\cline { 2 - 3 } \cline { 5 - 6 } & Before & After & & Before & After \\
\hline RSBI (cycles/min/L) & $97 \pm 47$ & $80 \pm 34$ & & $49 \pm 16$ & $48 \pm 10$ \\
& $\mathrm{P}=0.49$ & & & $\mathrm{P}=0.249$ & \\
$\mathrm{MIP}\left(\mathrm{cm} \mathrm{H}_{2} \mathrm{O}\right)$ & $43 \pm 16$ & $53 \pm 19$ & & $54 \pm 20$ & $61 \pm 17$ \\
& $\mathrm{P}=0.304$ & & & $\mathrm{P}=0.017$ & \\
\hline
\end{tabular}

INP: intermittent nebulization program; EIMT: electronic inspiratory muscle training; MIP: maximal inspiratory pressure; RSBI: rapid shallow breathing index.
$54 \pm 20 \mathrm{~cm} \mathrm{H}_{2} \mathrm{O}$ for the INP and EIMT groups, respectively. Taken together, this may explain the successful weaning and respiratory autonomy reached in both groups.

Jubran et al [20] compared patients weaned using decreasing support pressure with those weaned using INP at specific times daily. Weaning time in the INP group was shorter than that in the support pressure group. Conversely, the weaning time in the EIMT group in our study was shorter than that of the INP group.

In our study, RSBI was not significantly different between the two groups, both before and after training; this is in contrast to the study by Cader et al [18]. However, the population in their study was mainly composed of elderly individuals who were on MV for a shorter period and were trained while still on tracheal intubation; both these factors may have contributed to the significant decrease in RSBI. In our study, each patient had been tracheostomized and had an MV time of $21.8 \pm 9.8$ days in the INP group, and $14.5 \pm 10$ days in the EIMT group; it is likely for this reason that the RSBI did not decrease. Furthermore, the RSBI value in the EIMT group in our study was already within the predictive value for successful ventilatory weaning, i.e., less than 104 cycles/min/L, with a mean of $49 \pm$ 16 cycles $/ \mathrm{min} / \mathrm{L}$. However, patients were not yet able to acquire 
respiratory autonomy without respiratory muscle training.

With regards to the safety of the electronic device, the present study was in accordance with several previous studies $[11,21,22]$, all of which used the Threshold ${ }^{\mathbb{R}}$ IMT device in patients dependent on MV in the ICU. In contrast, we used the POWERbreathe ${ }^{\circledR} \mathrm{KH} 2$ in such patients. Therefore, the POWERbreathe ${ }^{\circledR} \mathrm{KH} 2$ is equally safe, because it did not significantly or sustainably affect the HR, MAP, RR, or $\mathrm{SpO}_{2}$ of the patients enrolled in this study, during or after training.

It is important to highlight that the POWERbreathe ${ }^{\circledR}$ was initially meant exclusively for IMT in healthy and fit individuals (16 recreational runner athletes) [15]. Thus, it was necessary to determine the safety and applicability of the instrument in this "off-label" use, namely, the weaning of tracheostomy patients. Information is still scarce in the literature regarding the utility of electronic IMT devices in patients whose condition is severe. In a case study involving tracheostomized patient with neuromuscular disease who had been MV-dependent for 14 days, Souza et al [16] reported successful IMT using the POWERbreathe ${ }^{\circledR}$; the study was carried out in an intermediate care unit. A 30-cm $\mathrm{H}_{2} \mathrm{O}$ increase in MIP was observed after 2 weeks, allowing $\mathrm{MV}$ discontinuation, decannulation, and initiation of non-invasive MV. Therefore, in accordance with the results of their study, the authors concluded that IMT was safe, as hemodynamic variables did not change to the point of interrupting the IMT, and there was no need to administer supplemental oxygen. More studies are necessary to understand when, how and for how long we need to implement the muscular training in intensive care medicine before and after weaning [23].

\section{Conclusions}

It can be concluded that the electronic IMT device is safe, as it did not adversely affect $\mathrm{HR}, \mathrm{MAP}$, and $\mathrm{SpO}_{2}$ variations. In addition, it may be effective since it led to an increase in MIP over pre-training values, and weaning time was shorter than in the INP group. Shorter weaning times in particular may contribute to a decrease in the incidence of MV-associated pneumonia and in hospital-acquired infection, as well as to shorter hospitalization times and, consequently, lower morbidity and mortality and decreased hospitalization-related costs.

\section{Acknowledgments}

The authors thank the research physiotherapists, students of specialization in physiotherapy, nurses, intensivists and $\mathrm{PhD}$ medical professors of the Intensive Care Unit of Clinics Hospital - UNICAMP for their help conducting research. Special thanks for the instrumental, technological support and partnership provided by Pedro Chocair and Angelina Wagner in the development of this research.

\section{References}

1. Tobin MJ, Laghi F, Jubran A. Narrative review: venti- lator-induced respiratory muscle weakness. Ann Intern Med. 2010;153(4):240-245.

2. Levine S, Nguyen T, Taylor N, Friscia ME, Budak MT, Rothenberg P, Zhu J, et al. Rapid disuse atrophy of diaphragm fibers in mechanically ventilated humans. N Engl J Med. 2008;358(13):1327-1335.

3. Hermans G, Agten A, Testelmans D, Decramer M, GayanRamirez $\mathrm{G}$. Increased duration of mechanical ventilation is associated with decreased diaphragmatic force: a prospective observational study. Crit Care. 2010;14(4):R127.

4. Arroliga A, Frutos-Vivar F, Hall J, Esteban A, Apezteguia C, Soto L, Anzueto A, et al. Use of sedatives and neuromuscular blockers in a cohort of patients receiving mechanical ventilation. Chest. 2005;128(2):496-506.

5. Pelosi P, Ferguson ND, Frutos-Vivar F, Anzueto A, Putensen C, Raymondos K, Apezteguia C, et al. Management and outcome of mechanically ventilated neurologic patients. Crit Care Med. 2011;39(6):1482-1492.

6. Brochard L, Thille AW. What is the proper approach to liberating the weak from mechanical ventilation? Crit Care Med. 2009;37(10 Suppl):S410-415.

7. Esteban A, Anzueto A, Frutos F, Alia I, Brochard L, Stewart TE, Benito S, et al. Characteristics and outcomes in adult patients receiving mechanical ventilation: a 28 -day international study. JAMA. 2002;287(3):345-355.

8. Penuelas O, Frutos-Vivar F, Fernandez C, Anzueto A, Epstein SK, Apezteguia C, Gonzalez M, et al. Characteristics and outcomes of ventilated patients according to time to liberation from mechanical ventilation. Am J Respir Crit Care Med. 2011;184(4):430-437.

9. Dasta JF, McLaughlin TP, Mody SH, Piech CT. Daily cost of an intensive care unit day: the contribution of mechanical ventilation. Crit Care Med. 2005;33(6):1266-1271.

10. Bissett B, Leditschke IA, Neeman T, Boots R, Paratz J. Weaned but weary: one third of adult intensive care patients mechanically ventilated for 7 days or more have impaired inspiratory muscle endurance after successful weaning. Heart Lung. 2015;44(1):15-20.

11. Bissett BM, Leditschke IA, Paratz JD, Boots RJ. Protocol: inspiratory muscle training for promoting recovery and outcomes in ventilated patients (IMPROVe): a randomised controlled trial. BMJ Open. 2012;2(2):e000813.

12. Martin AD, Smith BK, Davenport PD, Harman E, Gonzalez-Rothi RJ, Baz M, Layon AJ, et al. Inspiratory muscle strength training improves weaning outcome in failure to wean patients: a randomized trial. Crit Care. 2011;15(2):R84.

13. Bissett B, Leditschke IA, Green M. Specific inspiratory muscle training is safe in selected patients who are ventilator-dependent: a case series. Intensive Crit Care Nurs. 2012;28(2):98-104.

14. Tong TK, McConnell AK, Lin H, Nie J, Zhang H, Wang J. "Functional" inspiratory and core muscle training enhances running performance and economy. J Strength Cond Res. 2016;30(10):2942-2951.

15. McConnell AK, Griffiths LA. Acute cardiorespiratory responses to inspiratory pressure threshold loading. Med Sci Sports Exerc. 2010;42(9):1696-1703.

16. Cordeiro de Souza L, Campos JF, Daher LP, Furtado 
da Silva P, Ventura A, do Prado PZ, Brasil D, et al. Mechanical ventilation weaning in inclusion body myositis: feasibility of isokinetic inspiratory muscle training as an adjunct therapy. Case Rep Crit Care. 2014;2014:902541.

17. Cader SA, de Souza Vale RG, Zamora VE, Costa CH, Dantas EH. Extubation process in bed-ridden elderly intensive care patients receiving inspiratory muscle training: a randomized clinical trial. Clin Interv Aging. 2012;7:437-443.

18. Cader SA, Vale RG, Castro JC, Bacelar SC, Biehl C, Gomes MC, Cabrer WE, et al. Inspiratory muscle training improves maximal inspiratory pressure and may assist weaning in older intubated patients: a randomised trial. J Physiother. 2010;56(3):171-177.

19. Epstein CD, El-Mokadem N, Peerless JR. Weaning older patients from long-term mechanical ventilation: a pilot study. Am J Crit Care. 2002;11(4):369-377.

20. Jubran A, Grant BJ, Duffner LA, Collins EG, Lanuza
DM, Hoffman LA, Tobin MJ. Effect of pressure support vs unassisted breathing through a tracheostomy collar on weaning duration in patients requiring prolonged mechanical ventilation: a randomized trial. JAMA. 2013;309(7):671-677.

21. Condessa RL, Brauner JS, Saul AL, Baptista M, Silva AC, Vieira SR. Inspiratory muscle training did not accelerate weaning from mechanical ventilation but did improve tidal volume and maximal respiratory pressures: a randomised trial. J Physiother. 2013;59(2):101-107.

22. Patsaki I, Papadopoulos E, Sidiras G, Christakou A, Kouvarakos A, Markaki V. The effectiveness of inspiratory muscle training in weaning critically ill patients from mechanical ventilation. Hosp Chron. 2013;8(2):86-90.

23. Bissett BM, Leditschke IA, Neeman T, Boots R, Paratz $\mathrm{J}$. Inspiratory muscle training to enhance recovery from mechanical ventilation: a randomised trial. Thorax. 2016;71(9):812-819. 